\title{
Predictive Role of Mac-2 Binding Protein in Gastric Cancer Prognosis
}

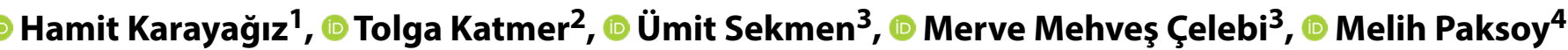 \\ ${ }^{1}$ Department of General Surgery, Acıbadem Healthcare Group, Acıbadem International Hospital, Istanbul, Turkey \\ ${ }^{2}$ Department of General Surgery, University of Health Sciences Turkey, Haydarpaşa Numune Training and Research Hospital, Istanbul, Turkey \\ ${ }^{3}$ Department of General Surgery, Acıbadem MAA University Faculty of Medicine, Istanbul, Turkey \\ ${ }^{4}$ Department of General Surgery, Acıbadem Healthcare Group, Acıbadem Fulya Hospital, Istanbul, Turkey
}

\begin{abstract}
Introduction: Gastric cancer is one of the most common and deadly cancers worldwide. Currently, it is becoming an overprevalent malignancy in Turkey. Early diagnosis and treatment have a pivotal role in ameliorating the prognosis in patients with gastric cancer. Mac-2 binding protein (Mac-2BP) is expressed in many types of tissues, and recent studies have demonstrated that it is upregulated in various cancerous tissues. We investigated the expression of Mac-2BP in patients with gastric cancer, as well as its association with clinical and pathological variables.

Methods: In this study, 130 patients, 90 patients with gastric cancer and 40 healthy controls were included. Serum Mac-2BP levels were measured in both groups. Clinical and pathological variables, including tumor size, histologic grade, primary tumor stage, lymph node metastasis, lymphatic invasion, vascular invasion, and neural invasion, were evaluated in the gastric cancer group.

Results: Circulating Mac-2BP levels were higher in patients with gastric cancer than the control group. Serum Mac-2BP levels especially elevated in patients with larger tumor size, poor histologic grade, advanced primary tumor stage, lymph node metastasis, lymphatic invasion, vascular invasion, and neural invasion.

Discussion and Conclusion: The findings obtained in this study suggest that serum Mac-2BP levels may have a predictive role in both gastric tumor diagnosis and prognosis.

Keywords: Gastric cancer; Mac-2 binding protein; Mac-2BP; metastases; prognosis.
\end{abstract}

G astric cancer remains one of the most common and deadly cancers worldwide ${ }^{[1]}$. Although its incidence has declined over the recent few decades, gastric cancer still has high mortality rates since it has no evident clinical symptoms in the early stages ${ }^{[2]}$. Hence, early diagnosis and treatment have a pivotal role in ameliorating the prognosis of patients with gastric cancer. However, despite the technological advancements in diagnosis with gastroscopy and im- munohistochemical analysis, these invasive procedures are still impractical for large-scale screening of gastric cancer ${ }^{[3]}$. Various diagnostic serum markers have been identified for gastric cancer, such as carcinoembryonic antigen (CEA), MG7-Ag ${ }^{[4]}$, MUC1, and MUC5AC ${ }^{[5]}$. The most common problem with almost all was due to their low sensitivities and specificities in cancer diagnosis, leading to their infrequent clinical use ${ }^{[6]}$. Compared to tissue and serum

Correspondence (iletişim): Merve Mehveş Çelebi, M.D. Acibadem MAA Universitesi, Tip Fakultesi, Genel Cerrahi Departmani, Istanbul, Turkey Phone (Telefon): +90 5387298341 E-mail (E-posta): mehvescelebi@gmail.com 
collection, urine collection is a more convenient and noninvasive technique. Thus, the urinary proteome analyses may be more advisable for large scale screenings, even for cancer detection, with possible biomarker discoveries in the future ${ }^{[7]}$. Various urinary biomarkers have already been used for gastric cancer, such as pepsinogen I, prostaglandin $\mathrm{E2}$, and soluble c-erb-B2 ${ }^{[8-10]}$. Similar to the other serum markers, these have not been commonly used for clinical diagnosis as well. Therefore, there is a considerable need for identification and approval of accredited diagnostic markers for screening gastric cancer.

Mac-2 binding protein (Mac-2BP) has been denominated as a $90-70 \mathrm{kDa}$ secreted glycoprotein that binds to human macrophage-associated lectin, called the Mac-2 antigen, and has been known as a member of the macrophage scavenger receptor family that enclose the cysteine-rich domain $^{[11-13]}$. It has been demonstrated that Mac-2BP upregulates the expression of cell adhesion molecules on cultured tumor cells ${ }^{[14]}$. The present study aims to investigate the expression of Mac-2BP in patients with gastric cancer, as well as its association with clinical and pathological variables.

\section{Materials and Methods}

The subjects gave their oral and written informed consent before their inclusion in this study, allowing the use of their blinded clinical data for research purposes and publication. This study was conducted following the Declaration of Helsinki Principles as revised in 2013.

The study groups consisted of 90 patients with gastric cancer and 40 healthy controls who visited the Department of General Surgery of Acıbadem MAA University, Faculty of Medicine (Istanbul, Turkey). Mean age was $59.86 \pm 6.32$ years (range 43-73 years) in the patient group and 58.85 \pm 5.95 years (range 43-70 years) in the control group. The groups' female/male ratio was $43 \%(27 / 63)$ and $33 \%(10 / 30)$, respectively. Clinical and pathological variables, including tumor size, histologic grade, primary tumor stage, lymph node metastasis, lymphatic invasion, vascular invasion, and neural invasion, were evaluated in the gastric cancer group. None of the patients with gastric cancer received chemotherapy or radiotherapy before or after their surgery as a part of a (neo)adjuvant protocol.

Peripheral venous blood of patients with gastric cancer was withdrawn before their operation. Peripheral venous blood of healthy controls was withdrawn on the day of their physical examination. Immediately after collection, blood samples were centrifuged at $3000 \mathrm{rpm}$ for 10 minutes at $4{ }^{\circ} \mathrm{C}$ to aliquot the supernatants, which were then stored at $-80^{\circ} \mathrm{C}$ until the analysis. When the supernatants were thawed for analysis, they were centrifuged at $10000 \mathrm{rpm}$ for five minutes at $4{ }^{\circ} \mathrm{C}$ to remove any precipitate. Serum Mac-2BP levels were measured with 'sandwich-type' enzyme-linked immunosorbent assay (ELISA) kits (Human Mac-2BP ELISA kit (code: ab119502), ABCAM Systems, USA). The procedures were performed in accordance with the manufacturer's instructions. The sensitivity was $0.92 \mathrm{ng} / \mathrm{mL}$ (range $12.5-200 \mathrm{ng} / \mathrm{mL}$ ).

\section{Statistical Analysis}

Statistical analyses were performed using the Statistical Package for the Social Sciences software version 21.0 (SPSS, Inc., Chicago, IL, USA). Continuous variables were described using mean, standard deviation (SD), median, minimum, maximum, and frequency and were given as a percentage. All variables were normally distributed based on the Shapiro-Wilk normality test and one-sample Kolmogorov-Smirnov test, and histogram with Q-Q plot and box plot graphs were drawn. Independent variables of the two groups were analyzed using t-test (Independent Samples T-Test) and Mann-Whitney $U$ test according to their parametric/non-parametric nature. Groups that have more than two categories were evaluated by the Kruskal-Wallis one-way analysis of variance. A Bonferroni correction was made after primary statistical tests as needed. Nominal variables were evaluated using Pearson's chi-square test with Yates's continuity correction. A p-value of $<0.05$ was considered significant.

\section{Results}

Table 1 provides the demographic variables. The two groups did not differ in age $(p=.673)$ or gender $(p=.581)$. Table 2 provides comparison of serum levels of Mac-2BP

Table 1. Demographic variables of healthy controls and patients with gastric cancer

\begin{tabular}{lccc}
\hline & Controls $(\mathbf{n = 4 0})$ & Patients $(\mathbf{n = 9 0 )}$ & $\mathbf{p}$ \\
\hline Mean Age & $58.85 \pm 5.95$ & $59.86 \pm 6.32$ & 0.673 (N.S.) \\
Gender (F/M) & $10 / 30$ & $27 / 63$ & 0.581 (N.S.)
\end{tabular}

N.S. $=$ Not Significant $(p>.05),{ }^{*} p<.05,{ }^{* *} p<.01,{ }^{* * *} p<.001$.

Table 2. Serum levels of Mac-2BP of healthy controls and patients with gastric cancer

\begin{tabular}{lccc}
\hline Controls $(\mathbf{n}=40)$ & Patients $(\mathbf{n}=90)$ & $\mathbf{p}$ \\
\hline Mean Mac-2BP $(\mathrm{ng} / \mathrm{mL})$ & $20.11 \pm 2.38$ & $148.10 \pm 54.58<0.001^{* * *}$
\end{tabular}

N.S. $=$ Not Significant $(p>.05),{ }^{*} p<.05,{ }^{* *} p<.01,{ }^{* * *} p<.001$ 
between groups. The mean serum Mac-2BP level was $20.11 \pm 2.38 \mathrm{ng} / \mathrm{mL}$ (range 12.5-25.5) in the control group, and $148.10 \pm 54.58 \mathrm{ng} / \mathrm{mL}$ (range 40.2-192.5) in the patient group. The serum Mac-2BP levels were significantly higher in the patient group $(p<.001)$ (Fig. 1).

Table 3 provides clinical and pathological variables of healthy controls and patients with gastric cancer. The primary tumor stages of patients with gastric cancer were TI ( $n=9)$, TII $(n=18)$, TIII $(n=22)$, and TIV $(n=41)$. The serum Mac-2BP levels were significantly higher with TIV tumors compared to TI tumors ( $\mathrm{p}<.001$; after Bonferroni correction $\mathrm{p}<.0083$ ) (Fig. 2). Furthermore, tumor stages also differ in the levels of Mac-2BP $(p<.001)$. Our results also indicated a correlation between mean serum Mac-2BP levels and tumor size, as higher Mac-2BP levels were detected in patients with tumor greater than $3 \mathrm{~cm}$ compared to patients who had tumor smaller than $3 \mathrm{~cm}$ in the largest diameter $(p=.004)$. Additionally, serum Mac-2BP levels were higher in patients with gastric cancer with poor histologic grade, lymph node metastasis, lymphatic invasion, vascular invasion, and neural invasion $(p=.002, p=.003, p=.001$, $\mathrm{p}=.001, \mathrm{p}=.001$, respectively). Bonferroni-corrected Man$\mathrm{n}$-Whitney test was used for binary comparisons; the limit of significance $p<.167$ was included. Accordingly, all the categories are different from each other $(p<.001)$.

Tumor size, histologic grade, primary tumor stage, and lymph node metastasis were not confounded by the age variable between the groups $(p=.639, p=.648, p=.572$, $\mathrm{p}=.645$, respectively). Gender variable was not a confounding factor for lymph node metastasis and lymphatic invasion between both groups ( $p=.732, p=.635$, respectively). Moreover, gender was distributed homogeneously between the primary tumor stages $(p=.855)$.

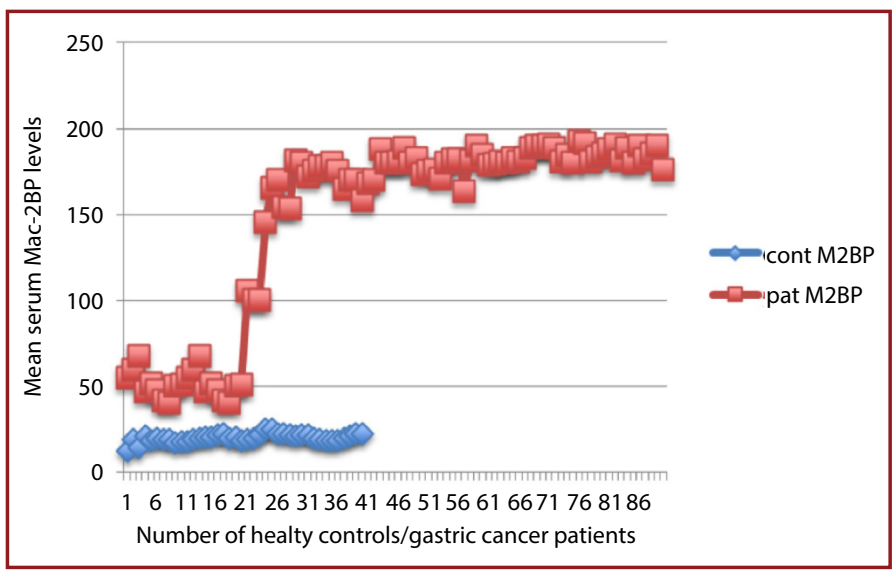

Figure 1. The histogram for mean serum Mac-2BP levels of healthy controls and patients with gastric cancer.
Table 3. Clinical and pathological variables of healthy controls and patients with gastric cancer

\begin{tabular}{|c|c|c|}
\hline & Patient Group $(n=90)$ & $\mathbf{p}$ \\
\hline \multicolumn{3}{|l|}{ Tumor Size } \\
\hline$<3 \mathrm{~cm}(\mathrm{n}=15)$ & $48.89 \pm 7.89$ (38.4-68) & $0.004^{* *}$ \\
\hline$>3 \mathrm{~cm}(\mathrm{n}=75)$ & $171.44 \pm 24.10(98.7-192.5)$ & \\
\hline \multicolumn{3}{|l|}{ Histologic Grade } \\
\hline Well $(n=10)$ & $51.34 \pm 8.26(40.2-68.0)$ & $0.002^{* *}$ \\
\hline Moderate $(n=22)$ & $105.37 \pm 55.56(40.2-181.4)$ & \\
\hline Poor $(n=58)$ & $180.99 \pm 7.42(158.3-192.5)$ & \\
\hline \multicolumn{3}{|l|}{ Primary Tumor Stage } \\
\hline $\mathrm{TI}(\mathrm{n}=9)$ & $51.35 \pm 8.77(40.2-68.0)$ & $<0.001^{* * *}$ \\
\hline TII $(n=18)$ & $83.68 \pm 46.14(40.2-170.0)$ & \\
\hline TIII $(n=22)$ & $175.33 \pm 8.70(153.7-188.5)$ & \\
\hline $\operatorname{TIV}(n=41)$ & $183.01 \pm 6.17(163.7-192.5)$ & \\
\hline \multicolumn{3}{|c|}{ Lymph Node Metastasis } \\
\hline$(-)(n=11)$ & $51.67 \pm 7.92(40.2-68.0)$ & $.003^{* *}$ \\
\hline$(+)(n=79)$ & $161.53 \pm 43.55(40.2-192.5)$ & \\
\hline \multicolumn{3}{|l|}{ Lymphatic Invasion } \\
\hline$(-)(n=13)$ & $53.56 \pm 8.74(40.2-68.0)$ & $.001^{* *}$ \\
\hline$(+)(n=77)$ & $164.06 \pm 41.10(40.2-192.5)$ & \\
\hline \multicolumn{3}{|l|}{ Vascular Invasion } \\
\hline$(-)(n=12)$ & $52.36 \pm 7.92(40.2-68.0)$ & $.001^{* *}$ \\
\hline$(+)(n=78)$ & $162.83 \pm 42.26(40.2-192.5)$ & \\
\hline \multicolumn{3}{|l|}{ Neural Invasion } \\
\hline$(-)(n=15)$ & $53.02 \pm 8.27(40.2-68.0)$ & $.001^{* *}$ \\
\hline$(+)(n=75)$ & $167.12 \pm 37.03(40.2-192.5)$ & \\
\hline
\end{tabular}

N.S. $=$ Not Significant $(p>.05),{ }^{*} p<.05,{ }^{* *} p<.01,{ }^{* * *} p<.001$.

Using ROC (receiver operating characteristic) curve analysis, a serum Mac-2BP cut-off value of $25.0 \mathrm{ng} / \mathrm{mL}$ provided the best discrimination between patients with gastric cancer and healthy controls.

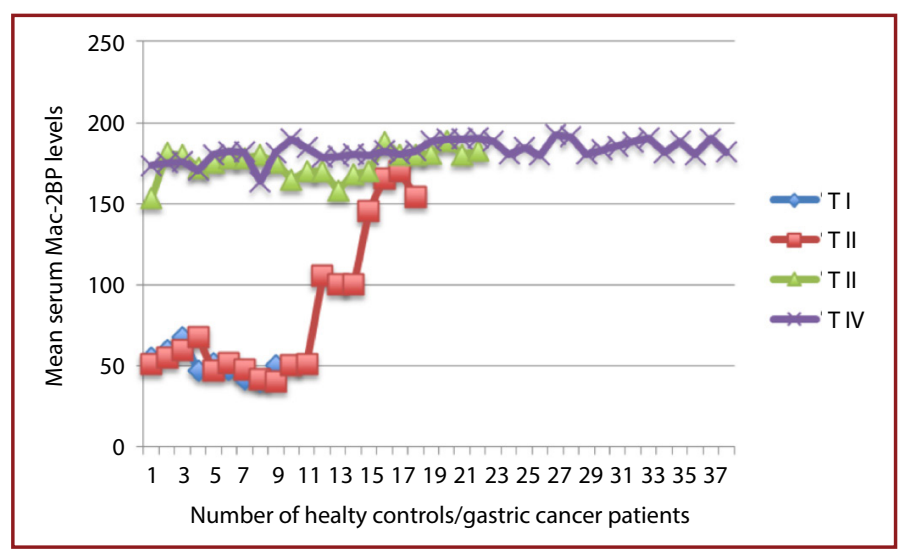

Figure 2. The histogram for mean serum Mac-2BP levels of patients with gastric cancer according to the primary tumor stages. 


\section{Discussion}

Human tumor cells may express numerous substances jointly referred as tumor antigens and release them into circulation. Serological analysis of these antigens in cancer patients has been used both for diagnosis and guidance for metastasis ${ }^{[4,5]}$. Mac-2BP is one of these tumor-derived antigens that have been recently emerging, and the present study investigated its relationship with gastric cancer.

Our data indicate two main findings regarding Mac-2BP in gastric cancer: first, the level of Mac-2BP expression in gastric cancer correlates with clinical and pathological variables; second, the level of serum Mac-2BP concentration emerges to be exacerbated in advanced gastric cancer.

The correlation between the measured levels of Mac-2BP expression and clinical and pathological variables of patients with gastric cancer leads us to the result that higher levels of circulating Mac-2BP are observed in advanced gastric carcinoma. On the other hand, we accredit that the clinical and pathological prominence of Mac-2BP tested in the tumor or in the serum may be all over dissimilar, since it yields dissimilar processes. The intracellular Mac-2BP basin has been adduced to contain only remnant measures of the completely glycosylated $94 \mathrm{kDa}$ protein ${ }^{[13]}$. It may intervene with dissimilar biological activities as regards the mature protein secreted in the serum. Its production may be part of the inflammatory response to neoplasia. Our results suggest this may be the reason behind high levels of Mac-2BP expression in patients with gastric cancer as compared with healthy individuals. Thus, we conclude that the increased amount of Mac-2BP in the serum is associated with poor prognosis ${ }^{[15]}$.

As a tumor-associated glycoprotein which interacts with galectins and has roles in host defense by augmenting the immune response, high levels of Mac-2BP is reported to be correlated and modulated with the malignant prognosis and distal metastasis of colon cancer ${ }^{[16,17]}$. Also, similar findings were reported for several other cancers, such as higher serum Mac-2BP levels, which indicate poor prognosis in colorectal cancer ${ }^{[18]}$, diffuse large B-cell lymphoma ${ }^{[19]}$, and lung cancer ${ }^{[20]}$.

In our study, we demonstrated that serum Mac-2BP levels could be a predictor for the advanced invasion of gastric cancer. To our knowledge, the effects of Mac-2BP on gastric cancer prognosis and its role in carcinogenesis have not been yet extensively studied in the literature. Mac-2BP may administer a cross-linking bridge between the tumor cells, and proffering a role in embolization and dispersion of tumor cells in the circulation. Its virtue on tumor growth and progression are amended by dissimilar Mac-2BP domain of discrete glycosylation. Therefore, future studies are necessary to clarify the framing and function of this noteworthy protein in cancer.

\section{Conclusion}

Increased amount of Mac-2BP expression is seen in patients with gastric cancer as compared with healthy individuals. Larger tumor size, poor histologic grade, advanced primary tumor stage, lymph node metastasis, lymphatic invasion, vascular invasion, and neural invasion are the clinical and pathological variables that correlate with higher levels of circulating Mac-2BP in patients with gastric cancer.

Peer-review: Externally peer-reviewed.

Authorship Contributions: Concept: H.K., T.K., Ü.S.; Design: H.K., T.K., Ü.S.; Data Collection or Processing: H.K., T.K., Ü.S., M.P.; Analysis or Interpretation: H.K., Ü.S., M.M.Ç.; Literature Search: H.K., M.M.Ç.; Writing: H.K., T.K., Ü.S., M.M.Ç., M.P.

Conflict of Interest: None declared.

Financial Disclosure: The authors declared that this study received no financial support.

\section{References}

1. Jemal A, Bray F, Center MM, Ferlay J, Ward E, Forman D. Global cancer statistics. CA Cancer J Clin 2011;61:69-90. [CrossRef]

2. Wu K, Nie Y, Guo C, Chen Y, Ding J, Fan D. Molecular basis of therapeutic approaches to gastric cancer. J Gastroenterol Hepatol 2009;24:37-41. [CrossRef]

3. Gurzu S, Orlowska J, Sugimura H, Bara T, Szentirmay Z, Januszewicz $W$, et al. Immunohistochemical features and staging of early gastric cancer. Arch Med Sci 2017;13:1373-82.

4. Ren J, Chen Z, Juan SJ, Yong XY, Pan BR, Fan DM. Detection of circulating gastric carcinoma-associated antigen MG7-Ag in human sera using an established single determinant immunopolymerase chain reaction technique. Cancer 2000;88:280-5.

5. $\mathrm{Xu} \mathrm{Y,} \mathrm{Zhang} \mathrm{L}, \mathrm{Hu}$ G. Potential application of alternatively glycosylated serum MUC1 and MUC5AC in gastric cancer diagnosis. Biologicals 2009;37:18-25. [CrossRef]

6. Kon OL, Yip TT, Ho MF, Chan WH, Wong WK, Tan SY, et al. The distinctive gastric fluid proteome in gastric cancer reveals a multi-biomarker diagnostic profile. BMC Med Genomics 2008;1:54. [CrossRef]

7. Adachi J, Kumar C, Zhang Y, Olsen JV, Mann M. The human urinary proteome contains more than 1500 proteins, including a large proportion of membrane proteins. Genome Biol 2006;7:R80. [CrossRef]

8. Yamaguchi T, Takahashi T, Yokota T, Kitamura K, Noguchi A, Kamiguchi $M$, et al. Urinary pepsinogen I as a tumor marker of stomach cancer after total gastrectomy. Cancer 1991;68:906-9.

9. Dong LM, Shu XO, Gao YT, Milne G, Ji BT, Yang G, et al. Urinary 
prostaglandin E2 metabolite and gastric cancer risk in the Shanghai women's health study. Cancer Epidemiol Biomarkers Prev 2009;18:3075-8. [CrossRef]

10. Tsigris C, Karayiannakis AJ, Syrigos KN, Zbar A, Diamantis $\mathrm{T}$, Kalahanis $\mathrm{N}$, et al. Clinical significance of soluble c-erbB-2 levels in the serum and urine of patients with gastric cancer. Anticancer Res 2002;22:3061-5.

11. lacobelli S, Arnò E, D'Orazio A, Coletti G. Detection of antigens recognized by a novel monoclonal antibody in tissue and serum from patients with breast cancer. Cancer Res 1986;46:3005-10.

12. lacobelli S, Bucci I, D'Egidio M, Giuliani C, Natoli C, Tinari N, et al. Purification and characterization of a $90 \mathrm{kDa}$ protein released from human tumors and tumor cell lines. FEBS Lett 1993;319:59-65. [CrossRef]

13. Ullrich A, Sures I, D'Egidio M, Jallal B, Powell TJ, Herbst R, et al. The secreted tumor-associated antigen $90 \mathrm{~K}$ is a potent immune stimulator. J Biol Chem 1994;269:18401-7.

14. Natoli $C$, lacobelli $S$, Kohn L. The immune stimulatory protein 90K increases major histocompatibility complex class I expression in a human breast cancer cell line. Biochem Biophys Res Commun 1996;225:617-20. [CrossRef]
15. lacobelli S, Sismondi P, Giai M, D'Egidio M, Tinari N, Amatetti C, et al. Prognostic value of a novel circulating serum $90 \mathrm{~K}$ antigen in breast cancer. Br J Cancer 1994;69:172-6. [CrossRef]

16. Schoeppner HL, Raz A, Ho SB, Brealier RS. Expression of anendogenous galactose-binding lectin correlates with neoplastic progression in the colon. Cancer 1995; 75:2818-26. [CrossRef]

17. Sanjuán X, Fernández PL, Castells A, Castronovo V, van den Brule F, Liu FT, et al. Differential expression of galectin 3 and galectin 1 in colorectal cancer progression. Gastroenterology 1997;113:1906-15. [CrossRef]

18. lacovazzi PA, Notarnicola M, Caruso MG, Guerra V, Frisullo S, Altomare DF, et al. Serum levels of galectin-3 and its ligand $90 \mathrm{k} / \mathrm{mac}-2 \mathrm{bp}$ in colorectal cancer patients. Immunopharmacol Immunotoxicol 2010;32:160-4. [CrossRef]

19. Kim SJ, Lee SJ, Sung HJ, Choi IK, Choi CW, Kim BS, et al. Increased serum $90 \mathrm{~K}$ and Galectin-3 expression are associated with advanced stage and a worse prognosis in diffuse large B-cell lymphomas. Acta Haematol 2008;120:211-6. [CrossRef]

20. Ozaki Y, Kontani K, Teramoto K, Fujita T, Tezuka N, Sawai S, et al. Involvement of 90K/Mac-2 binding protein in cancer metastases by increased cellular adhesiveness in lung cancer. Oncol Rep 2004;12:1071-7. [CrossRef] 